\title{
The challenge of growing oral spirochaetes
}

\author{
HELEN M. WARDLE \\ Department of Microbiology, Salford Royal Hospitals Trust, Hope Hospital, Stott Lane, Salford M6 8HD
}

\begin{abstract}
Research in periodontal disease has shown the presence of oral spirochaetes repeatedly in subgingival plaque. There is uncertainty as to whether these spirochaetes are involved in the actual disease process; however, it has been shown that their presence is a definite marker for disease occurrence. An understanding of their role in periodontal disease requires further characterisation of these organisms. Diagnostic tests would be useful for the clinician and enable treatment for the patient to be planned. Studies on characterising the different treponemal species have been limited by difficulties in culturing these organisms. Moreover, there is a need to obtain pure cultures of these organisms and to identify them in order to associate particular species with disease and, ultimately, to make probes for their easy detection directly from dental plaque. This review examines the methods used, and reports our own experience, in obtaining pure cultures of oral spirochaetes. The techniques available and the problems that occur when identifying these organisms are also considered.
\end{abstract}

\section{Introduction}

Many groups of investigators have observed oral spirochaetes of various Treponema species repeatedly in subgingival plaque from patients with periodontal disease [1-3]. These organisms are numerically the predominant species seen in periodontal pockets in what is often a diverse microbial population [4-6]. Whether these spirochaetes contribute to the severity of periodontal disease is a matter of debate $[7,8]$; however, it seems certain that their presence is a definite indicator that disease processes are occurring [9-11]. It has also been demonstrated that $T$. denticola is often found in the presence of Porphyromonas gingivalis [11], suggesting that pre-colonisation by other bacteria may be necessary for growth and infection with $T$. denticola to occur. This association underlines the importance of isolating and cultivating these treponemes, with a view to identifying them and, ultimately, to evaluating their role in the development of periodontitis.

Because of the difficulties associated with culturing the oral treponemes - which have extremely low oxygen tolerance [12] and complex nutritional requirements $[13,14]$ - it has proved difficult to enumerate accurately a particular species of treponeme from the oral cavity. Counts of the number of spirochaetes are

Received 16 May 1996; revised version accepted 16 July 1996.

Corresponding author: Ms H. M. Wardle. obtained usually by darkfield, or phase-contrast, microscopy and cytoimmunochemistry [15]. However, this does not provide any indication as to which species of treponeme is present and can give only an overall picture of the relative numbers of spirochaetes. It is uncertain which treponeme species is the most prolific in the subgingival plaque. Some studies have found that $T$. denticola was the organism isolated most frequently $[16,17]$, whereas others found that $T$. socranskii was cultivated most frequently and was usually the most numerous organism among the cultivable treponemes [18]. There is a distinction between which treponeme is present in the highest numbers and which treponeme is isolated most frequently, as these are not necessarily one and the same. Methods of isolation and cultivation used, particularly with respect to media, play a large part in determining which species of treponeme are isolated. It has been found that different treponeme species have very different nutritional requirements and, therefore, may be isolated selectively by the use of a particular type of medium $[18,19]$. The difficulty experienced in culturing the treponemes has led to the development of other methods to detect and quantify these organisms, including use of immunological reagents [20, 21] and DNA probes [22-24].

\section{Selection of patients}

Periodontitis is inflammation that extends to periodontal structures beyond the gingiva, producing a loss 
of connective tissue attachment to the tooth. The American Academy of Periodontology recommend a classification containing five primary forms of periodontitis - prepubertal, juvenile, adult, rapidly progressive and acute necrotising ulcerative gingivo-periodontitis. In most of the studies in which spirochaetes have been observed or isolated, the patients have been from one of these groups [1, 25, 26]. In studies of specific periodontal patients, the extent of disease is assessed by the use of indices such as the Periodontal Index (PI) [27], the Periodontal Disease Index (PDI) [28] and the indices devised by the International Dental Federation and the World Health Organization [29]. For our own purposes - i.e., to obtain samples of subgingival plaque that were likely to contain spirochaetes - any patient attending the periodontal clinic of the Turner Dental Hospital of Manchester with a clinical assessment of periodontitis was sampled.

\section{Sampling methods}

Various methods are used for sampling subgingival plaque from patients with periodontal disease. Examples of the procedures used by different investigators are listed in Table 1 [3, 16, 17, 30-35]. Studies have been carried out to ascertain the method of sampling that will yield the most organisms [36] and to determine the area from which it is appropriate to take the sample [25]. Microscopic observation has shown that these bacteria are localised mainly on the loose surface layer of plaque that is in contact with pocket epithelium [15]. In our own studies, paperpoints have been inserted into the periodontal pocket for $10 \mathrm{~s}$, to collect subgingival plaque.

\section{Transport fluid}

One of the most important factors in the initial sampling of subgingival plaque is the maintenance of viability of the organisms present in the sample. Frequently, samples are collected in a clinic which may be some distance from the laboratory where culture is to be carried out [30]. Thus, techniques are required that retain the relative proportions of the different organisms present in plaque to reflect the situation in vivo. The importance of keeping the sampling-to-analysis time as short as possible when analysing the motility of oral organisms has been stressed previously [37]. It is generally thought that the best way to do this is by placing the scaler, curette or paper-point in transport fluid that will allow survival of these organisms. Different constituents can be added to the transport medium to improve its efficacy (Table 2) $[16,30,31,35,38]$. It is known that the spirochaetes are deficient in antioxidant enzymes [39]; therefore, one of the most important medium components is a reducing agent to ensure a low redox potential. For example, dithiothreitol can be added to give a low Eh [40]. It is also important to use a balanced mineral salt solution that will maintain the organisms' viability without multiplication, so that the relative proportions of each organism will remain constant. The transport fluid used in this laboratory is the Reduced Transport Fluid (RTF) described by Loesche et al. [30]. A study that investigated the survival of human dental plaque flora in three types of transport media - RTF, VMG II and modified Stuart medium (SBL) - found that RTF did not allow the growth of oral bacteria, but appeared the most appropriate medium for recovery of bacteria from periodontal plaque specimens [41].

Table 1. Examples of methods used to sample subgingival plaque

\begin{tabular}{ll}
\hline Method of sampling & 30 \\
\hline Teeth not air-dried; buccal surface plaque removed with periodontal scalers & Reference \\
Teeth isolated with cotton rolls; sample sites dried with sterile cotton swabs; supragingival plaque \\
removed with sterile toothpicks; subgingival plaque collected with a Morse 00 scaler \\
Supragingival plaque removed and then collected with a fine curette \\
Gingival crevice debris collected with sterile toothpicks \\
Supragingival plaque removed by curette, with a second curette used to remove subgingival plaque \\
Teeth isolated with sterile cotton rolls; supragingival plaque removed with sterile cotton rolls; subgingival plaque \\
collected with a paper-point inserted for $20 \mathrm{~s}$ \\
Supragingival plaque removed, with subgingival plaque collected with a curette \\
\hline
\end{tabular}

Table 2. Examples of transport fluid used by different groups of investigators

\begin{tabular}{lll}
\hline Transport fluid & Constituents \\
\hline VMG IV & Agar, Bacto-gelatine, tryptose, thiotone, cysteine $\mathrm{HCl}$, thioglycollic acid, stock salt solution* \\
RTF & $\mathrm{Na}_{2} \mathrm{CO}_{3}$, EDTA, dithiothreitol, $\mathrm{K}_{2} \mathrm{HPO}_{4}, \mathrm{KH}_{2} \mathrm{PO}_{4}, \mathrm{NaCl},\left(\mathrm{NH}_{4}\right)_{2} \mathrm{SO}_{4}, \mathrm{MgSO}_{4}$ \\
Sterile diluent & Two parts chopped meat broth, three parts salt solution & 38 \\
Sterile saline & $0.85 \mathrm{~N}$ sterile saline & 31 \\
Transport medium & Brain heart infusion, L-cysteine, resazurin, agar & 16 \\
\hline
\end{tabular}

${ }^{*}$ Stock salt solution containing phenylmercuric acid, $\mathrm{CaCl}_{2} \cdot 6 \mathrm{H}_{2} \mathrm{O}, \mathrm{KCl}, \mathrm{NaCl}, \mathrm{MgSO}_{4} \cdot 7 \mathrm{H}_{2} \mathrm{O}$, sodium glycerophosphate, methylene blue. 


\section{Dispersion methods}

Dental plaque is formed by sequential colonisation and growth of micro-organisms on the surfaces of teeth, soft tissues, restorations and oral appliances. It consists of many different species embedded in an extracellular matrix made-up of components from saliva, food and serum. Because of the physical nature of plaque, it may be difficult to separate the individual organisms for culture. Therefore, various methods have been employed to try and disperse the plaque sample in the transport medium, of which the most common is mechanical mixing (e.g., by vortex). As spirochaetes are particularly fragile organisms, care must be taken to make sure they are not disrupted by the procedure employed. Salvador et al. [17] compared three dispersion procedures - sonication, mechanical mixing and homogenisation - for the recovery of cultivable species of subgingival spirochaetes. It was concluded that the highest viable recovery of spirochaetes was achieved by dispersion with a Tekmar homogeniser. However, spirochaetes comprised c.56\% of the microscopic count, but only $1 \%$ of the cultivable flora after homogenisation, suggesting either that the spirochaetes observed were uncultivable or that the procedure used was too harsh for their survival. Sonication has been used to disperse plaque samples [41, 42], and several studies [3, 18, 43] have used the conventional dispersion method of mechanical mixing with a vortex mixer or 'whirlimix', sometimes combined with sonication [44, 45], with successful results. However, some workers consider that sonic oscillation should not be used to disperse organisms in dental samples because treponemes are destroyed by sonication [31]. It has also been reported that the addition of EDTA to transport fluid can aid in the dispersion process [30]. Our own studies have found that vortex mixing samples for $20 \mathrm{~s}$ gives good dispersion of plaque without disrupting the spirochaetes.

\section{Primary isolation}

When culturing a plaque sample for many different organisms, a non-selective medium should be used initially to attempt to grow all the bacteria in the same proportions. However, when organisms are present in low numbers, or are difficult to culture in the presence of other organisms, it is necessary to use selective media for primary isolation. Many different media (Table 3) [16, 17, 30, 31, 46-49] have been used in an attempt to select for oral treponemes, and most recent studies have tended to use a modification of one or more of these media.

Supplements added to the base medium also determine the type of treponemes that are selected. It is generally thought that the oral treponemes can be grouped into two categories - those requiring serum (or serum + thiamine pyrophosphate), and those requiring rumen fluid (and glucose and pectin). Therefore, to isolate both groups of spirochaetes, a general purpose medium containing all these components is required. It has been found that a fatty acid mixture can be used instead of rumen fluid [46]. This overcomes the supply and standardisation problems associated with the use of rumen fluid.

Some authors have determined the specific media requirements of individual species with complex chemically defined media. Wyss [14] developed 'OMIZ-WI' medium, which supports growth of a wide range of oral anaerobes. $T$. denticola strain CD-1 grew in the absence of polyamines and long-chain fatty acids, $T$. pectinovorum and $T$. socranskii required polyamines, whereas $T$. vincentii depended on both polyamines and lecithin for growth [14]. Van Horn and Smibert [50] found that $T$. denticola and $T$. vincentii required albumin, oleic acid and thiamine pyrophosphate (TPP) for growth. They also found that

Table 3. Examples of media used for selection of oral spirochaetes

\begin{tabular}{|c|c|c|}
\hline Medium & Constituents & Reference \\
\hline M10 & $\begin{array}{l}\text { Glucose, cellobiose, soluble starch, } \mathrm{KH}_{2} \mathrm{PO}_{4}, \mathrm{NaCl},\left(\mathrm{NH}_{4}\right)_{2} \mathrm{SO}_{4}, \mathrm{~K}_{2} \mathrm{HPO}_{4}, \mathrm{CaCl}_{2}, \mathrm{MgSO}_{4} .7 \mathrm{H}_{2} \mathrm{O} \text {, } \\
\mathrm{Na}_{2} \mathrm{CO}_{3} \text {, trypticase, yeast extract, volatile fatty acids, haemin, agar }\end{array}$ & 46 \\
\hline MM10 & $\begin{array}{l}\text { Agar, trypticase, yeast extract, } \mathrm{K}_{2} \mathrm{HPO}_{4}, \mathrm{NaCl},\left(\mathrm{NH}_{4}\right)_{2} \mathrm{SO}_{4}, \mathrm{MgSO}_{4} \text {, haemin, } \mathrm{KNO}_{3} \text {, sheep blood, } \\
\text { glucose, } \mathrm{Na}_{2} \mathrm{CO}_{3} \text {, dithiothreitol, menadione, fatty acids }\end{array}$ & 30 \\
\hline GM-1 & $\begin{array}{l}\text { Trypticase, yeast extract, } \mathrm{NaCl} \text {, sodium thioglycolate, } \mathrm{L} \text {-cysteine } \mathrm{HCl} \text {, thiamine pyrophosphate, } \\
\text { volatile fatty acids, sodium bicarbonate, rabbit serum }\end{array}$ & 47 \\
\hline Laughon & $\begin{array}{l}\text { Trypticase peptone, yeast extract, gelatin, heart infusion broth, glucose, cysteine } \mathrm{HCl} \text {, } \\
\left(\mathrm{NH}_{4}\right)_{2} \mathrm{SO}_{4}, \mathrm{MgSO}_{4}, \mathrm{~K}_{2} \mathrm{HPO}_{4}, \mathrm{KH}_{2} \mathrm{PO}_{4}, \mathrm{NaCl} \text {, thiamine pyrophosphate, rabbit serum }\end{array}$ & 48 \\
\hline OTI & $\begin{array}{l}\text { Peptone, heart infusion broth base, yeast extract, ribose, pectin, glucose, fructose, starch, } \\
\text { sucrose, maltose, sodium pyruvate, } \mathrm{K}_{2} \mathrm{HPO}_{4}, \mathrm{NaCl},\left(\mathrm{NH}_{4}\right)_{2} \mathrm{SO}_{4} \text {, cysteine } \mathrm{HCl} \text {, haemin, } \\
\text { vitamin } \mathrm{K} 1 \text {, resazurin, rumen fluid, serum-yeast autolysate-TPP }\end{array}$ & 31 \\
\hline NOS (modified) & $\begin{array}{l}\text { Heart infusion broth, trypticase, yeast extract, sodium thioglycolate, } \\
\text { L-cysteine } \mathrm{HCl} \text {, L-asparagine, glucose, noble agar, thiamine pyrophosphate, } \\
\text { volatile fatty acids, sodium bicarbonate, rabbit serum }\end{array}$ & 16 \\
\hline Fiehn's & $\begin{array}{l}\text { Brain heart infusion broth, noble agar, rabbit serum, horse blood, co-carboxylate, } \\
\text { rifampicin, polymixin B, nalidixic acid }\end{array}$ & 49 \\
\hline MTYGVS & $\begin{array}{l}\text { Tryptone, heart infusion broth, yeast extract, gelatin, }\left(\mathrm{NH}_{4}\right)_{2} \mathrm{SO}_{4}, \mathrm{MgSO}_{4} .7 \mathrm{H}_{2} \mathrm{O} \text {, } \\
\mathrm{K}_{2} \mathrm{HPO}_{4}, \mathrm{NaCl} \text {, noble agar, glucose, cysteine } \mathrm{HCl} \text {, thiamine } \mathrm{PPi} \text {, sodium pyruvate, } \\
\text { volatile fatty acids, rabbit serum, pectin }\end{array}$ & 17 \\
\hline
\end{tabular}


short-chain fatty acids supported only limited growth of $T$. denticola in a medium combined with TPP or $\mathrm{TPP}+$ de-lipified albumin $0.4 \% \mathrm{w} / \mathrm{v}$. Smibert and Burmeister [19] specified in their description of $T$. pectinovorum that it required either rumen fluid or short-chain volatile fatty acids and a fermentable energy source such as pectin, polygalacturonic acid, glucuronic acid or galacturonic acid. T. socranskii has similar requirements [19]. However, Chan et al. [51] described $T$. denticola as being primarily an aminoacid fermenter that does not use the glycolytic pathway as a major energy source. This study found that only sodium bicarbonate was essential for growth of the six treponeme isolates investigated.

Once the appropriate medium has been selected there are two main methods by which treponemes can be isolated from other dental organisms. The first involves supplementing the medium with antibiotics to enhance selectivity. Only a limited range of antibiotics is suitable, but good results have been achieved with either rifampicin [34, 52], rifampicin and polymixin [18, 31, 53], or nalidixic acid [49]. Preliminary experiments have suggested that antibiotic resistance may be associated with a low affinity of the spirochaete RNA polymerase for rifampicin [34]. The second method uses membrane filtration to achieve mechanical separation of treponemes from other organisms. However, even a membrane pore size of $0.2 \mu \mathrm{m}$ does not necessarily limit the filtration of organisms above this size as the treponemes are able to migrate through areas smaller than their overall width because of their spiralling type of motility and absence of a rigid cell wall [54]. Nitrocellulose membrane filters with a pore size of $0.2-0.3 \mu \mathrm{m}$ are often used, and many investigators, including ourselves, have found that a combination of antibiotics and filtration achieves the best results [16,51]. Our own studies have found that modified New Oral Spirochaete (NOS) media, as described by Leschine and Canale-Parola [34], supplemented with rifampicin $4 \mathrm{mg} / \mathrm{L}$ is appropriate for primary isolation of oral treponemes. The NOS plates are poured to a greater thickness than usual to withstand the drying that accompanies long periods of incubation in the anaerobic cabinet. The plates should be transferred to the cabinet at least a few hours before work is carried out to pre-reduce them. Once inside the cabinet, $0.2 \mu \mathrm{m}$ or $0.45 \mu \mathrm{m}$ nitrocellulose membrane filters are placed on to each NOS plate with sterile forceps. Plaque suspension $(100 \mu \mathrm{l})$ is then inoculated on to the respective NOS plate in the centre of the filter and left overnight to absorb. The plates are then put into sterile plastic bags and fastened with elastic bands to reduce contamination from within the anaerobic cabinet. In the past, some investigators have placed a sterile O-ring on top of the filter and sealed it to the filter with molten agar $3 \% \mathrm{w} / \mathrm{v}$ in water [55].

The length of time that these primary isolation plates are incubated varies, but it is generally thought that between 1 and 2 weeks is needed to permit observable growth of oral spirochaetes in the medium. Cheng and Chan [16] incubated plates for 10 days before removal of the membrane filters, whereas Smibert et al. [18] incubated plates for 2 weeks to isolate $T$. socranskii. One of the main problems with these extended incubation periods is that the plates are more prone to contamination by organisms present in the cabinet, e.g., Bacillus spp., or by other larger dental organisms migrating over the filter, e.g., Capnocytophaga spp., or contamination of the spirochaetes beneath the filter by other small dental organisms that have been able to migrate through the filter, e.g., Campylobacter spp. In cases where continual cabinet contamination is occurring, it may be necessary to fumigate the cabinet. To reduce the risk of this type of contamination, plates for long-term incubation can be incubated within sterile plastic bags. Contamination by other plaque organisms can also be reduced by removing the membrane filter after incubation for 4 days and taking plugs of agar from beneath the filter, even though growth cannot be observed by eye. This procedure minimises the growth of other organisms, but enough viable spirochaetes are usually present to grow in the secondary inoculum.

\section{Recovery and secondary inoculation}

After incubation of the primary isolation plates, various methods have proved satisfactory in our hands to recover any spirochaetes obtained. The membrane filter is removed with sterile forceps and the agar underneath is checked for white hazy or fluffy growth. An initial plug of agar can be taken with a pasteur pipette and checked for the presence of treponemes by dark-field microscopy. This initial check is imperative because other organisms can also produce hazy sub-surface colonies that may be mistaken for the growth of treponemes. Once growth of spirochaetes is confirmed, further plugs of agar can be taken and inoculated into either agar or broth to increase the numbers of spirochaetes in an enclosed environment. This procedure has several advantages: (i) there is less risk of contamination from external sources; (ii) the oxygen content can be minimised; and (iii) the bottles can be kept for longer periods of time without dessication.

At this stage, different investigators have developed their own methods of inoculation to suit individual laboratory facilities and equipment. Smibert and Burmeister [19] inoculated the plugs of agar containing hazy growth into pre-reduced OTI broth (Table 3) in rubber-stoppered tubes. After incubation, the treponemes were inoculated into pre-reduced OTI broth in rubber-stoppered bottles containing molten OTI agar, mixed and placed flat until the agar gelled. These cultures were then incubated at $37^{\circ} \mathrm{C}$ for $1-3$ weeks and observed for the development of colonies. 
Single well-isolated colonies were then picked and inoculated into OTI broth. Cheng and Chan [16] followed a slightly different procedure, picking the spirochaete growth with a transfer needle and performing serial dilutions in molten NOS agar (Table 3) plus rifampicin $(2 \mathrm{mg} / \mathrm{L})$. These dilutions were placed in a glove-box, cooled to $45^{\circ} \mathrm{C}$ and then poured into petri dishes and incubated for 10 days to obtain isolated colonies. The colonies were then inoculated into soft NOS agar medium (containing Noble agar $0.3 \% \mathrm{w} / \mathrm{v}$ ) with no rifampicin in screw-capped tubes. Alternatively, the initial plaque solution can be diluted before inoculating the diluted solutions into culture medium [35].

Several different methods of inoculation and culture have been tried in our own laboratory with varying success. The best method in our hands involved primary incubation for 4-7 days, after which the filters were removed with sterile forceps and discarded. Three separate plugs of agar were taken with sterile insulin needles and syringes (Terumo, Leuven, Belgium) from the site beneath the filter and inoculated into small sterile glass bottles containing NOS semi-solid agar (NOS agar containing CTA medium). These were incubated at $37^{\circ} \mathrm{C}$ and observed every few days for hazy or fluffy white growth of spirochaetes. The presence of spirochaetes was confirmed by dark-ground microscopy, modified Gray's stain or a modified Gram's stain. Occasionally single colonies could be obtained directly by this method (Fig. 1), but it was often necessary to streak the spirochaetes on to plates of NOS agar to obtain discreet single colonies (Fig. 2).

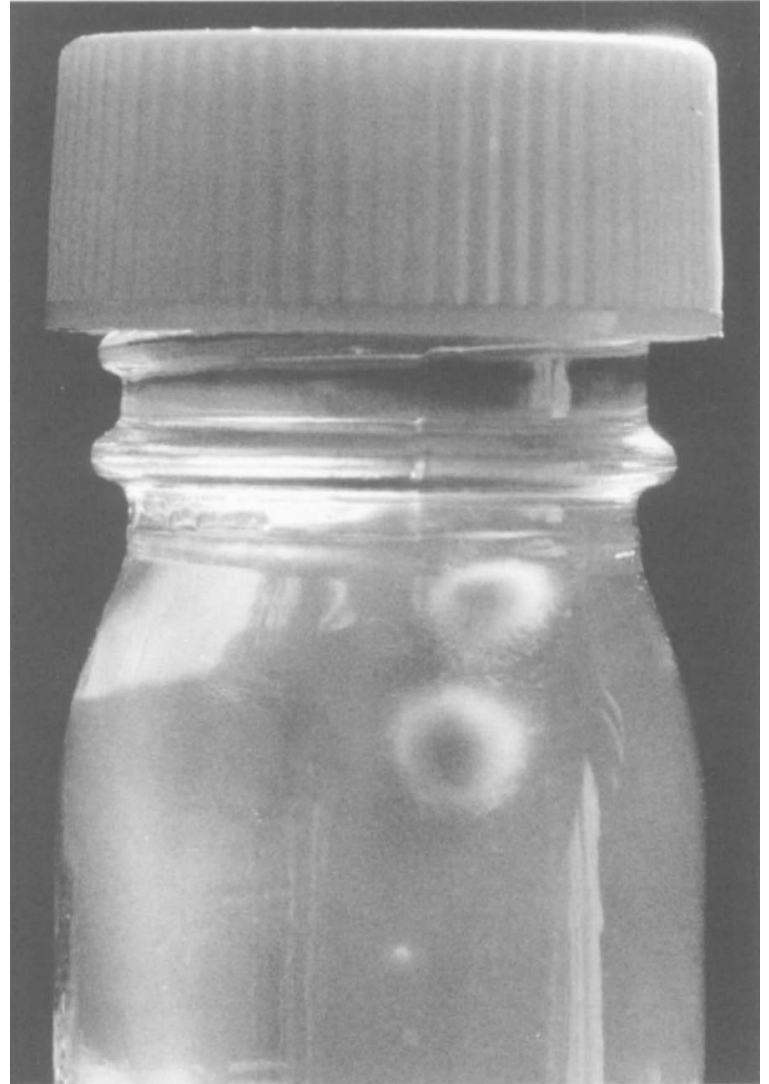

Fig. 1. Single colonies of oral spirochaetes from a clinical sample isolated in NOS semi-solid agar.

Sometimes it was unclear as to whether the original 'single colony' had developed from the growth of one single spirochaete species or a number of species.

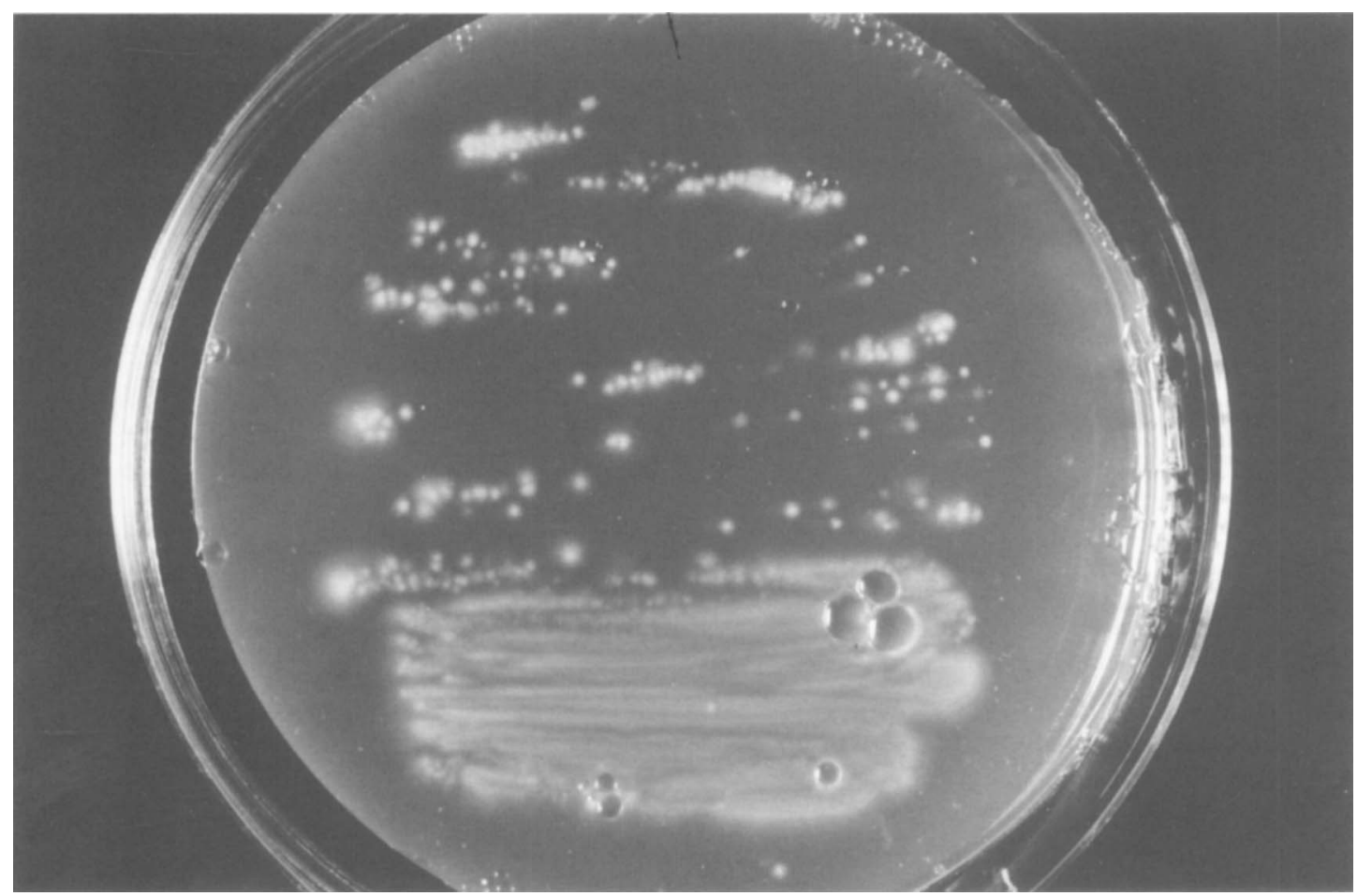

Fig. 2. Single colonies of oral spirochaetes from a clinical sample following streaking on to NOS agar. 


\section{Production of pure culture}

The method used in our laboratory gives discreet single colonies which can then be picked off from the agar plate with a sterile pasteur pipette and inoculated into NOS broth. Following incubation at $37^{\circ} \mathrm{C}$ for $4-7$ days for growth to occur, each culture is checked for purity by dark-ground microscopy, staining or streaking out on to other media (e.g., blood agar) before further analysis.

An unusual observation sometimes made after growth of spirochaetes in either broth or semi-solid agar for longer periods is the development of a black film on the surface of the culture (Fig. 3). Initially this was thought to be contamination by another organism, but dark-ground microscopy followed by electron microscopy revealed that only spirochaetes were present. Furthermore, it was found that most of these spirochaetes were coiled (Fig. 4). It was concluded that this phenomenon must have occurred because the spirochaetes were either old, or stressed because of the presence of oxygen, as it appeared to be present only at the surface of the culture. The presence of granular bodies in cultures of spirochaetes has been described

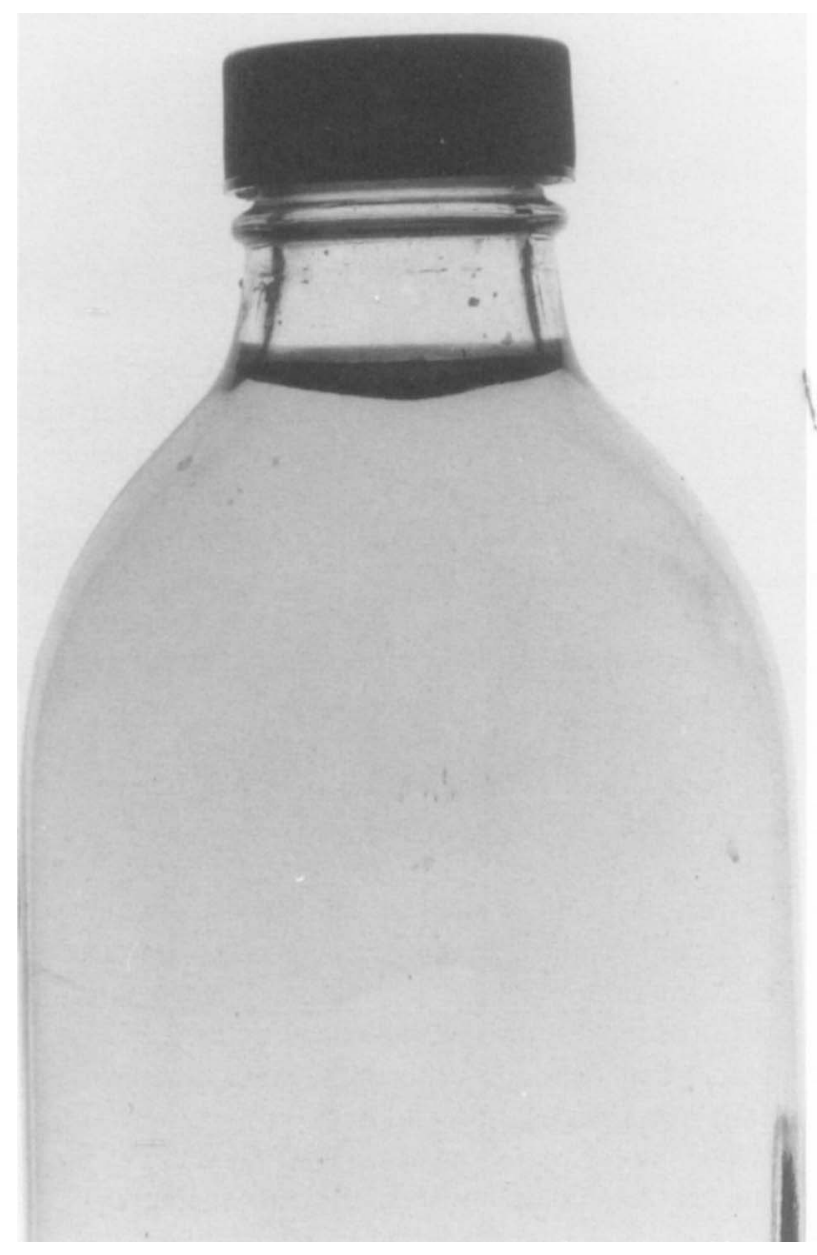

Fig. 3. Development of a black film - one of the phenomena that can occur when growing oral spirochaetes in broth for longer periods. for at least 90 years. It has been debated whether these granular or spheroidal forms are stages in the spirochaete life cycle or are degenerative forms that do not take part in the life cycle or infectivity.

Blake [56] studied by electron microscopy the cultured vesicular forms of spirochaetes derived from acute ulcerative gingivitis. When freshly inoculated filter cups were exposed to air for $24 \mathrm{~h}$, there was rapid production of vesicles filled with unwalled spirochaete bodies, which suggested that the vesicular form was influenced by unfavourable conditions. Furthermore, cultures were able to grow when anaerobic conditions were re-established, suggesting that the vesicular forms were indeed viable. More recently, Wolf et al. [57] described the development of quasi-multicellular bodies of $T$. denticola. These bacteria develop four different types of structure: (i) normal helical forms; (ii) twisted spirochaetes, forming plaits; (iii) twisted spirochaetes, forming club-like structures; and (iv) spherical bodies of different sizes. 'Plaits', 'clubs' and 'spherical bodies' were found predominantly in culture sediments, whereas helical spirochaetes were found mainly in the supernate. It was also found that all morphological forms could be observed after 2-3 days when sediment enriched with spherical bodies or supernatant fluid was inoculated into fresh medium, indicating that these are all viable forms. It was suggested that morphological variation may be connected with survival strategy, and that the formation of spherical structures would reduce surface area and so present less target area for the action of antibodies or toxic agents.

\section{Storage and maintenance of isolates}

Both clinical isolates and culture collection strains of treponemes can be maintained by a number of methods, including monthly transfers into fresh medium [16]. The obvious problem with this method is one of contamination, particularly with regard to cultures in broth. There is also a chance of loss of viability of the organism so that subsequent transfers are not possible. Some investigators have found that freezing of the cultures at $-70^{\circ} \mathrm{C}$ or in liquid nitrogen is appropriate for long-term maintenance of these sensitive organisms [19]. Some media constituents act as cryoprotective agents when cultures are frozen, e.g., DMSO, polyvinylpyrolidine or glycerol broth [58]. It is not clear whether lyophilisation is an appropriate method for long-term preservation of spirochaetes, but the American Type Culture Collection (ATCC) maintains some of their treponeme cultures in a freeze-dried state.

\section{Identification}

Once a pure culture of a treponeme isolate has been cultivated, it is possible to characterise and, ultimately, 
Fig. 4. Coiled appearance of oral spirochaete strain $\mathrm{PH} / 54 \mathrm{~b}$ taken from the black film illustrated in Fig. 3.

identify the organism. This can be a difficult procedure, not least because it can be difficult to relate new findings to previous reports. The main problem is that investigators in the past have isolated what they have thought to be 'new' treponemes, characterised them by various methods and then named them. Frequently, such cultures subsequently became non-viable so that further work could not be performed. Furthermore, there is a lack of consistency of nomenclature between different laboratories, so that the same organism may be referred to by two different names.

For laboratories that are new to investigating the characteristics of clinical isolates of treponemes and that do not have access to strains from other sources to use as comparators, the only available treponemes are those maintained by ATCC. At the present time, ATCC have only two approved species of oral Treponema - T. pectinovorum (strain ATCC 33768) and $T$. socranskii, consisting of three subspecies: $T$. socranskii subsp. buccale (strain ATCC 35534); subsp. paredis (strain ATCC 35535); and subsp. socranskii (strain ATCC 35536). ATCC also have four different isolates designated as ' $T$. denticola' (strains ATCC 33520, ATCC 33521, ATCC 35404 and ATCC 35405) and one of ' $T$. vincentii' (strain ATCC 35580).

\section{Structure}

Spirochaetes can be characterised morphologically by electron microscopy. One of the main characteristics used by investigators is the number of axial filaments present in the internal structure. For example, a 2-4-2 arrangement indicates two filaments inserted at each end of the organism which then overlap, usually centrally in the organism, to give four. Problems arise with this method of characterisation when authors are ambiguous in their description of the organisms, e.g., referring to them as having two axial filaments. Does this mean two at each end (i.e., 2-4-2) or one at each end (i.e., 1-2-1) to give a total of two?

It is very difficult to analyse the overall configuration of a pure culture, even by electron microscopy, because the spirochaetes sometimes have different configurations within the same culture (Fig. 5). It is apparent that there are different filament arrangements as the spirochaetes are dividing, or have previously divided, so that it appears that there are more filaments than usual. Listgarten and Socransky [59] described a diagrammatic model of the dividing spirochaete to illustrate this phenomenon. It is also apparent that different filament arrangements have been observed within the same treponeme strain. Chan 


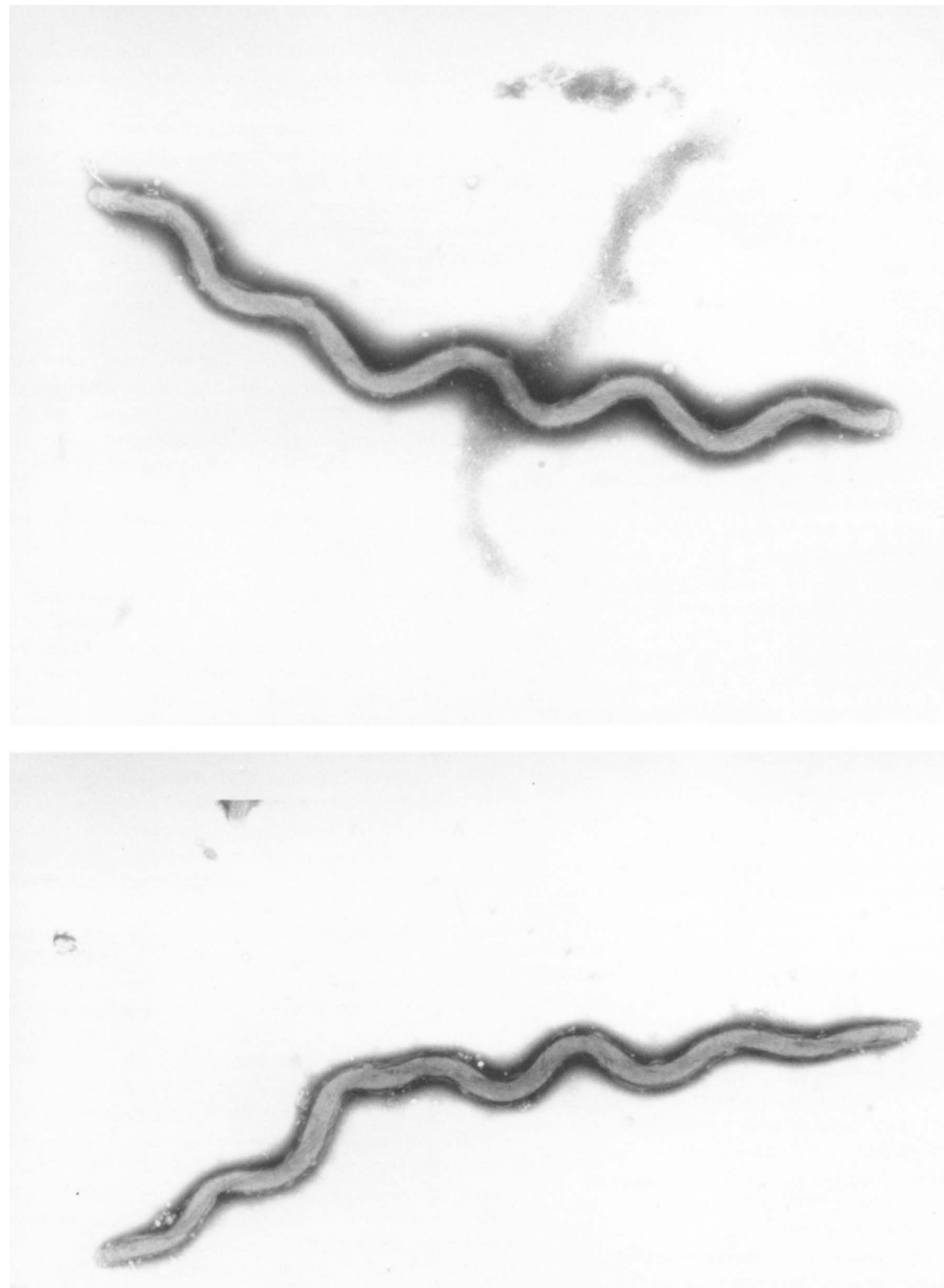

Fig. 5. Cells of oral spirochaete strain $\mathrm{PH} / 63 \mathrm{a}$ with different axial filament arrangements (A, magnification $\times 13500$; B, magnification $\times 10500$ ). 
et al. [51] described $T$. denticola strain ATCC 35405 as having 10 axial filaments - and therefore a 5-10-5 endoflagella arrangement - whereas, in previous studies, $T$. denticola strains have been documented as having 2-4-2, 3-6-3 and 5-10-5 arrangements [16, $53,60]$.

Other parameters that have been used to characterise the spirochaetes are width or cell diameter, amplitude, wavelength and cell length $[55,61]$. However, different studies have reported different measurements for the same strain, and there is insufficient difference between strains to enable these measurements to be used as distinguishing features.

\section{Determination of metabolic end-products}

When spirochaetes are grown in the absence of oxygen, they produce intermediate products consisting of short-chain fatty and organic acids and alcohols. As the enzymes responsible for metabolism are genetically stable, the end-products produced provide a fingerprint that is distinctive for a particular species or closely related species [62]. Analysis of volatile and non-volatile fatty acids can be achieved by gas liquid chromatography (GLC). The peaks on the resulting trace correspond to different acids and these can be compared to a set of standards that are analysed at the same time. The spirochaetes are grown in broth to a sufficient density for analysis. For analysis of volatile fatty acids, $0.2 \mathrm{ml}$ of $\mathrm{H}_{2} \mathrm{SO}_{4}$ $50 \% \mathrm{v} / \mathrm{v}$ and $1 \mathrm{ml}$ of ether are added to each $1 \mathrm{ml}$ of broth. This is shaken in a glass test tube for $0.5 \mathrm{~min}$ and centrifuged to separate the layers. The ether (upper) layer is pipetted into a stoppered plastic centrifuge tube. The sample is treated in the same way for analysis of non-volatile fatty acids, except that $0.4 \mathrm{ml}$ of $\mathrm{H}_{2} \mathrm{SO}_{4} 50 \% \mathrm{v} / \mathrm{v}$ is used and methanol is added in place of ether. The mixture is stoppered and heated in a water bath at $56^{\circ} \mathrm{C}$ for $30 \mathrm{~min}$, after which $1 \mathrm{ml}$ of water and $1 \mathrm{ml}$ of chloroform are added to the cooled mixture. This is stoppered, shaken and centrifuged to separate the layers, and the chloroform (lower) layer is then carefully pipetted off. Fermentation products of some oral treponemes have been described in the Anaerobe Laboratory Manual [63], but of the treponemes listed in the Manual, only $T$. denticola and $T$. vincentii are available from ATCC. There is also a conflict of opinion in the literature as to which peaks are produced by which species. As with other organisms, it has been found that various factors can influence the end-products produced by these spirochaetes. An important factor to be considered is the components of the growth medium used. The ratio of the concentration of carbohydrates to peptone may influence the acids produced [64-66]. Therefore, the medium constituents must be noted when analysing any data produced.

\section{Growth requirements and biochemistry}

Cultivable oral treponemes have different growth requirements. Some species ferment glucose and require a carbohydrate as an energy source, whereas other species obtain their energy from the fermentation of amino acids [61]. Treponemes also differ in their requirements for fatty acids. Some species require long-chain fatty acids found in serum, whereas others require short-chain volatile fatty acids found in rumen fluid. Therefore, their growth in different types of media can be used as a distinguishing feature for a particular organism.

A range of biochemical tests has been used in the past to characterise different species. These tests include hydrolysis of cellulose, aesculin, hippurate, dextrin, glycogen, starch and gelatin, blackening of mucin $1 \%$ media, utilisation of lactate and pyruvate, growth in the presence of $\mathrm{NaCl} 3 \%$ and bile $1 \%, \mathrm{H}_{2} \mathrm{~S}$ production, phosphatase activity, indole production and growth in glycine $1 \%$.

Knowledge of the enzymic activities of treponemes is a useful aid in their identification. A rapid test procedure, API ZYM (Analytab Products, Plainview, NY, USA), which uses chromogenic substrates to detect 19 enzyme activities, has been used by some authors to differentiate between treponeme species. Laughon et al. [48] found that the key differential tests for $T$. denticola and $T$. vincentii were trypsin and $N$-acetyl- $\beta$-glucosaminidase, with $T$. denticola being positive only for trypsin and $T$. vincentii being positive only for $N$-acetyl- $\beta$-glucosaminidase. In a study on the enzyme activities of eight small-sized oral spirochaetes, Fiehn [53] assayed the enzymes with the API ZYM system, by $p$-nitroanilide derivatised peptides, and by hydrolysing mucopolysaccharides incorporated into solid medium. The spirochaetes analysed - which were all of 2-4-2 endoflagella configuration - were also all negative for $N$-acetyl- $\beta$ glucosaminidase and positive for trypsin, which appeared to be in agreement with the results of Laughon et al. [48]. All the spirochaetes tested had active peptidases, phosphoamidase, acid phosphatase, hyaluronidase and chondroitin sulphatase. This finding has implications for the role played by spirochaetes in the development of marginal periodontitis, as all these enzymes are potentially destructive for host tissues. Another system that can analyse the enzymic reactions of oral Treponema spp. is RapID-ANA, and this system has been shown to distinguish between $T$. denticola, T. vincentii and T. socranskii [67].

\section{Immunoassay}

Various immunoassay techniques for the identification of oral spirochaetes are available. One of the most popular methods uses monoclonal antibodies (MAbs) in an immunoenzyme technique to stain spirochaetes directly in dental plaque. Barron et al. [68] used this 
technique to stain and identify specific treponemes within a plaque sample. The method permitted staining of single bacterial cells and, with use of the appropriate $\mathrm{MAb}$, identification of genus, species and serotype. Simonson et al. [11] used a quantitative enzyme-linked immunosorbant assay (ELISA) with MAbs specific for $T$. denticola and $P$. gingivalis to determine the levels of these organisms in plaque samples. In a study by van Poperin and Lopatin [69], a slot immunoblot assay was used to detect and quantify $T$. denticola and $P$. gingivalis in dental plaque, and this rapid method was found to be appropriate for detecting specific organisms of known identity.

Indirect fluorescent-antibody techniques have also been used to detect specific bacteria in clinical samples. Kearns et al. [70] produced MAbs that were able to distinguish between $T$. denticola strain ATCC 33521 (serotype B) and $T$. denticola strain ATCC 33520 (serotype C) with no cross-reactivity.

There are obvious limitations in the use of MAbs as a means of identifying unknown treponeme species. Most investigators have used this method as a means of detecting particular treponeme species or for showing the presence of spirochaetes in general. Thus, the identification of an unknown spirochaete is limited by the availability of particular MAb probes. If the spirochaete is one to which a MAb has not been made, then it will not be detected. Secondly, investigators must ensure that the MAbs used are very specific to the organism they are detecting, and that there is no cross-reactivity with other species, otherwise this method is not appropriate as a specific method of identification.

\section{Gene probes}

Because of the difficulties in culture-based identification procedures for oral treponemes, new methods of characterisation are being investigated continually. The first problem in identifying a pure culture of a treponeme isolate is actually growing enough of the isolate to perform the various tests needed. Secondly, it has been shown by many investigators that cultivation of treponemes does not reflect accurately either the amounts or types of treponemes that are present in the subgingival plaque [3].

Amann et al. [71] showed that use of a probe increased the number of organisms detected 10-fold compared with culture, thereby reflecting the difficulty in cultivating micro-organisms from natural systems. Therefore, many investigators have decided to explore gene probes as a means of detecting and identifying treponemes in dental plaque. Loesche et al. [3] compared various methods for detection of periodontopathic bacteria and found that DNA probes and immunological reagents were as efficient as microscopy for the detection of $T$. denticola. Some investigators have reported that detection by DNA probe is 1000 -fold more sensitive than semi-quantitative techniques such as ELISA and dot-blots [72]. A species-specific probe can be derived from either the bacterial DNA (genomic probe) or from synthesised short lengths of DNA (oligonucleotide probe). Species-specific oligonucleotides derived from variable regions of the 16S rRNA gene have already been developed for several oral bacteria [23, 24, 73]. Probes based on rRNA sequences have an additional advantage of increased sensitivity because they can be designed to be complementary to both the genomic DNA and the cellular rRNA. DNA probes for $T$. denticola and T. pectinovorum have been developed by OmniGene Inc. (Cambridge, MA, USA) based on labelling whole-cell genomic DNA. However, it has been shown that this type of probe is suitable for use only on pure cultures and does not have the required specificity for analysing mixed samples, especially if closely related species are involved [73]. Random amplification of polymorphic DNA (RAPD) fragments is another potential source of species-specific probes and the suitability of such probes for use with the treponemes is currently under investigation.

It can be seen, therefore, that there is great potential for the use of gene probes in the detection and identification of Treponema spp. in subgingival plaque. If a complete 'library' of probes was compiled of known species of treponemes, then the presence or absence of these organisms could be confirmed rapidly. Furthermore, specific probes for unknown species isolated from clinical samples can potentially be developed so that these new species can be detected again. This shows the importance of the initial development of a pure culture of an organism which can be consulted for further reference.

\section{Conclusions}

From the numerous studies investigating periodontal disease, it would seem that there is little doubt that the spirochaetes are either an important marker of, or are involved actively in, the disease process. However, in order to study their role in the pathogenesis of the disease, it is necessary to isolate and grow individual species of spirochaetes. Only then will it be possible to determine whether they play an active part in periodontal deterioration or whether they are simply influencing the habitat of other organisms of a more pathogenic nature. Riviere et al. $[74,75]$ found that pathogen-related oral spirochaetes (PROS) were present in plaque from patients with chronic adult periodontitis, and also plaque from HIV patients with periodontal disease [76]. PROS have been shown to be the only plaque organisms capable of invading living tissue in an in-vitro assay [77], while none of the cultivable oral spirochaetes was invasive. However, ability to invade tissues does not prove that PROS are pathogens and 
stresses the need for cultivation of these organisms to show their association with periodontal disease. Many different media and culture methods are available for growth and isolation of spirochaetes from dental plaque. There is a continuing need to experiment with different media and alternative culture techniques to isolate those spirochaetes that are presently uncultivable. Many of the clinical isolates obtained in pure culture by different investigators have characteristics similar to those of $T$. denticola. The use of a range of primary isolation media would be more appropriate to obtain a greater diversity of species.

The necessity for production of a pure culture of the isolate obtained cannot be stressed enough. It is a very time-consuming and tedious procedure to produce single colonies of spirochaetes from dental plaque. It is also very easy to contaminate a culture at any stage, so that continual checks must be made for purity throughout the procedure. There is also a need for comparator strains so that investigators in this subject can validate their own work. At present the ATCC has a limited collection of treponemes, of which only four strains belong to approved Treponema spp. Studies on all treponemes isolated are needed to verify their identification and it would be appropriate for these to be carried out by different investigating groups. There is a great need for standardisation in strain nomenclature to avoid the complexity of species names that has arisen in the past. From the identification methods described previously it can be seen that many of the traditional methods of characterisation are flawed techniques, and the results obtained with these methods have often not been sufficiently clear-cut to distinguish between different species. Nevertheless, more recently there have been vast improvements in both techniques and equipment, so that there is room for continued experimentation in these areas.

Finally, it is apparent that more studies are being based on genomic similarities as a means of identifying the oral spirochaetes. The genomic homologies between closely related species mean that the use of whole-cell DNA probes may not be appropriate for use with subgingival plaque because of its extreme diversity of species. The use of species-specific oligonucleotide probes is probably more suitable in this context. Ultimately, any diagnostic test for the oral spirochaetes needs to be both sensitive and specific if an accurate assessment of the Treponema spp. present is to be carried out. However, it remains obvious that in order to compare any 'new' oral treponeme with other species it will be necessary to obtain a pure culture of that organism. Furthermore, if additional work is to be carried out to investigate the pathogenesis of this organism, then a culture will be required that can be referred to at any time.

I am grateful to Drs D. W. Denning, D. B. Drucker, D. Law and L. A. Joseph (Hope Hospital) for their help and support in this work. I thank P. Hull (University of Manchester Dental School) for clinical samples, Drs A. Curry and H. Cotterill (Withington Hospital) for electron microscopy, and the Medical Illustration Department (Hope Hospital) for their photographic assistance. The support of this work by the North West Regional Health Authority is gratefully acknowledged.

\section{References}

1. Listgarten MA, Helldén L. Relative distribution of bacteria at clinically healthy and periodontally diseased sites in humans. $J$ Clin Periodontol 1978; 5: 115-132.

2. Listgarten MA, Lai C-H, Young V. Microbial composition and pattern of antibiotic resistance in subgingival microbial samples from patients with refractory periodontitis. $J$ Periodontol 1993; 64: 155-161.

3. Loesche WJ, Lopatin DE, Stoll J, van Poperin N, Hujoel PP. Comparison of various detection methods for periodontopathic bacteria: can culture be considered the primary reference standard? J Clin Microbiol 1992; 30: 418-426.

4. Harwood CS, Canale-Parola E. Ecology of spirochetes. Annu Rev Microbiol 1984; 38: 161-192.

5. Moore WEC, Holdeman LV, Cato EP et al. Comparative bacteriology of juvenile periodontitis. Infect Immun 1985; 48: 507-519.

6. Loesche WJ. The role of spirochetes in periodontal disease. Adv Dent Res 1988; 2: 275-283.

7. Lindhe J, Liljenberg B, Listgarten M. Some microbiological and histopathological features of periodontal disease in man. $J$ Periodontol 1980; 51: 264-269.

8. Simonson LG, Goodman CH, Bial JJ, Morton HE. Quantitative relationship of Treponema denticola to severity of periodontal disease. Infect Immun 1988; 56: 726-728.

9. Loesche WJ, Syed SA, Stoll J. Trypsin-like activity in subgingival plaque. A diagnostic marker for spirochaetes and periodontal disease? J Periodontol 1987; 58: 266-273.

10. Grenier D, Uitto V-J, McBride BC. Cellular location of a Treponema denticola chymotrypsin-like protease and importance of the protease in migration through the basement membrane. Infect Immun 1990; 58: 347-351.

11. Simonson LG, Robinson PJ, Pranger RJ, Cohen ME, Morton HE. Treponema denticola and Porphyromonas gingivalis as prognostic markers following periodontal treatment. $J$ Periodontol 1992; 63: 270-273.

12. Loesche WJ. Oxygen sensitivity of various anaerobic bacteria. Appl Microbiol 1969; 18: 723-727.

13. Fiehn NE, Westergaard J. Nutrient and environmental growth factors for eight small-sized oral spirochaetes. Scand $J$ Dent Res 1986; 94: 208-218.

14. Wyss C. Growth of Porphyromonas gingivalis, Treponema denticola, T. pectinovorum, T. socranskii, and $T$. vincentii in a chemically defined medium. J Clin Microbiol 1992; 30: 2225-2229.

15. Listgarten MA. Structure of the microbial flora associated with periodontal health and disease in man. A light and electron microscopic study. J Periodontol 1976; 47: 1-18.

16. Cheng S-L, Chan ECS. The routine isolation, growth, and maintenance of the intermediate-size anaerobic oral spirochaetes from periodontal pockets. J Periodont Res 1983; 18: $362-368$.

17. Salvador SL, Syed SA, Loesche WJ. Comparison of three dispersion procedures for quantitative recovery of cultivable species of subgingival spirochetes. $J$ Clin Microbiol 1987; 25: 2230-2232.

18. Smibert RM, Johnson JL, Ranney RR. Treponema socranskii sp. nov., Treponema socranskii subsp. socranskii subsp. nov., Treponema socranskii subsp. buccale subsp. nov., and Treponema socranskii subsp. paredis subsp. nov. isolated from human periodontia. Int $J$ Syst Bacteriol 1984; 34: 457-462.

19. Smibert RM, Burmeister JA. Treponema pectinovorum sp. nov. isolated from humans with periodontitis. Int $J$ Syst Bacteriol 1983; 33: 852-856.

20. Zambon JJ, Reynolds HS, Chen P, Genco RJ. Rapid identification of periodontal pathogens in subgingival dental plaque. Comparison of indirect immunofluorescence microscopy with bacterial culture for detection of Bacteroides gingivalis. J Periodontol 1985; 56 Suppl II: 32-40.

21. Gmur R. Applicability of monoclonal antibodies to quantita- 
tively monitor subgingival plaque for specific bacteria. Oral Microbiol Immunol 1988; 3: 187-191.

22. French CK, Savitt ED, Simon SL et al. DNA probe detection of periodontal pathogens. Oral Microbiol Immunol 1986; 1: $58-62$.

23. Dix K, Watanabe SM, McArdle $\mathrm{S}$ et al. Species-specific oligodeoxynucleotide probes for the identification of periodontal bacteria. J Clin Microbiol 1990; 28: 319-323.

24. Choi BK, Paster BJ, Dewhirst FE, Göbel UB. Diversity of cultivable and uncultivable oral spirochaetes from a patient with severe destructive periodontitis. Infect Immun 1994; 62: 1889-1895.

25. Katsanoulas T, Reneé I, Attsröm R. The effect of supragingival plaque control on the composition of the subgingival flora in periodontal pockets. J Clin Periodontol 1992; 19: 760-765.

26. Simonson LG, McMahon KT, Childers DW, Morton HE. Bacterial synergy of Treponema denticola and Porphyromonas gingivalis in a multinational population. Oral Microbiol Immunol 1992; 7: 111-112.

27. Russell AL. The Periodontal index. J Periodontol 1967: 38 Suppl: $585-591$.

28. Ramfjord SP. Indices for prevalence and incidence of periodontal disease. J Periodontol 1959; 30: 51-59.

29. Baume LJ, Marechaux SC. Standardization of the epidemiologic assessment of periodontal diseases. Surveys in the South Pacific. J Periodontol 1975; 46: 233-240.

30. Loesche WJ, Hockett RN, Syed SA. The predominant cultivable flora of tooth surface plaque removed from institutionalized subjects. Arch Oral Biol 1972; 17: 1311-1325.

31. Moore WEC, Holdeman LV, Smibert RM et al. Bacteriology of experimental gingivitis in young adult humans. Infect Immun 1982; 38: 651-667.

32. Moore WEC, Holdeman LV, Smibert RM, Hash DE, Burmeister JA, Ranney RR. Bacteriology of severe periodontitis in young adult humans. Infect Immun 1982; 38: 1137-1148.

33. Uitto VJ, Chan ECS, Quee TC. Initial characterization of neutral proteinases from oral spirochaetes. $J$ Periodont Res 1986; 21: 95-100.

34. Leschine SB, Canale-Parola E. Rifampicin as a selective agent for isolation of oral spirochaetes. J Clin Microbiol 1980; 12: $792-795$.

35. Umeda M, Ishikawa I, Benno $\mathrm{Y}$, Mitsuoka $\mathrm{T}$. Improved detection of oral spirochetes with an anacrobic culture method. Oral Microbiol Immunol 1990; 5: 90-94.

36. Renvert S, Wikström M, Helmersson M, Dahlén G, Claffey N Comparative study of subgingival microbiological sampling techniques. J Periodontol 1992; 63: 797-801

37. Petit MDA, Van der Velden U, Van Winkelhoff AJ, De Graff J. Preserving the motility of microorganisms. Oral Microbiol Immunol 1991; 6: 107-110.

38. Gästrin BLO, Kallings LO, Marcetic A. The survival time for different bacteria in various transport media. Acta Pathol Microbiol Scand 1968; 74: 371-380.

39. Park MK, Myers RAM, Marzella L. Oxygen tensions and infections: modulation of microbial growth, activity of antimicrobial agents, and immunologic responses. Clin Infect Dis 1992; 14: 720-740.

40. Cleland WW. Dithiothreitol, a new protective agent for $\mathrm{SH}$ groups. Biochemistry 1964; 3: 480-482.

41. Syed SA, Loesche WJ. Survival of human dental plaque flora in various transport media. Appl Microbiol 1972; 24: 638-644.

42. Gordon DF, Stutman M, Loesche WJ. Improved isolation of anaerobic bacteria from the gingival crevice area of man. Appl Microbiol 1971; 21: 1046-1050.

43. Dahle UR, Tronstad L, Olsen I. Observation of an unusually large spirochete in endodontic infection. Oral Microbiol Immunol 1993; 8: 251-253

44. Loesche WJ, Syed SA, Schmidt E, Morrison EC. Bacterial profiles of subgingival plaques in periodontitis. $J$ Periodontol 1985; 56: $447-456$.

45. Mombelli WJ, Minder CE, Gusberti FA, Lang NP. Reproducibility of microscopic and cultural data in repeated subgingival plaque samples. $J$ Clin Periodontol 1989; 16: 434-442.

46. Caldwell DR, Bryant MP. Medium without rumen fluid for nonselective enumeration and isolation of rumen bacteria. Appl Microbiol 1966; 14: 794-801.

47. Blakemore RP, Canale-Parola E. Arginine catabolism by
Treponema denticola. $J$ Bacteriol 1976; 128: 616-622.

48. Laughon BE, Syed SA, Loesche WJ. API ZYM system for identification of Bacteroides spp., Capnocytophaga spp., and spirochetes of oral origin. $J$ Clin Microbiol 1982; 15: 97-102.

49. Fiehn N-E, Frandsen A. Evaluation of serum-containing substrates for cultivation of oral spirochetes. $J$ Periodont Res 1984; 19: 61-66.

50. van Horn KG, Smibert RM. Albumin requirement of Treponema denticola and Treponema vincentii. Can J Microbiol 1983; 29: 1141-1148.

51. Chan ECS, Siboo R, Keng T et al. Treponema denticola (ex Brumpt 1925) sp. nov., nom. rev., and identification of new spirochete isolates from periodontal pockets. Int $J$ Syst Bacteriol 1993; 43: 196-203.

52. Stanton TB, Canale-Parola E. Enumeration and selective isolation of rumen spirochetes. Appl Environ Microbiol 1979; 38: $965-973$.

53. Fiehn N-E. Enzyme activities from eight small-sized oral spirochetes. Scand J Dent Res 1986; 94: 132-140.

54. Loesche WJ, Socransky SS. Defect in small millipore filters disclosed by new technique for isolating oral treponemes. Science 1962; 138: $139-140$

55. Smibert RM. Anaerobic spirochaetes. In: Lennette EH, Balows A, Hausler WJ, Shadomy HJ (eds) Manual of clinical microbiology, 4th edn. Washington DC, American Society for Microbiology. 1985: 490-494.

56. Blake GC. Electron microscopy of cultured vesicular forms of spirochaetes derived from acute ulcerative gingivitis. Dent Pract Dent Rec 1970; 20: 197-202.

57. Wolf V, Lange R, Wecke J. Development of quasi-multicellular bodies of Treponema denticola. Arch Microbiol 1993; 160: 206-213.

58. Gilmour MN, Turner G, Berman RG, Krenzer AK. Compact liquid nitrogen storage system yielding high recoveries of gram-negative anaerobes. Appl Environ Microbiol 1978; 35: $84-88$

59. Listgarten MA, Socransky SS. Electron microscopic study of axial flibrils, outer envelope and cell division of certain oral spirochetes. J Bacteriol 1964; 88: 1087-1103.

60. Loesche WJ. The spirochaetes. In: Nisengard RL, Newman MG (eds) Oral microbiology and immunology, 2nd edn. Philadelphia, Saunders. 1988: 228-236.

61. Smibert RM. Treponema. In: Krieg NR, Holt JG (eds) Bergey's Manual of systematic bacteriology, vol 1. Baltimore, Williams and Wilkins. 1984: 49-57.

62. Summanen P, Baron EJ, Citron DM, Strong CA, Wexler $\mathrm{H}$, Finegold SM. Wadsworth anaerobic bacteriology manual, 5th edn. Belmont, CA, Star. 1993.

63. Holdeman LV, Cato EP, Moore WEC. Anaerobe laboratory manual, 4th edn. Blacksburg, VA, Virginia Polytechnic and State University. 1977.

64. Turton LJ, Drucker DB, Ganguli LA. Effect of incubation time, calcium carbonate and glucose in the growth medium, upon the fermentation end-product profile of Clostridium difficile. Microbios 1982; 35: 7-16.

65. Turton LJ, Drucker DB, Ganguli LA. Effect of glucose concentration in the growth medium upon neutral and acidic fermentation end-products of Clostridium bifermentans, Clostridium sporogones and Peptostreptococcus anaerobius. $J$ Med Microbiol 1983; 16: 61-67.

66. Turton LJ, Drucker DB, Hillier VF, Ganguli LA. Effect of eight growth media upon fermentation profiles of ten anaerobic bacteria. J Appl Bacteriol 1983; 54: 295-304.

67. Syed SA, Salvador SL, Loesche WJ. Enzyme profiles of oral spirochetes in RapID-ANA system. J Clin Microbiol 1988; 26 2226-2228.

68. Barron SL, Riviere GR, Simonson LG, Lukehart SA, Tira DE, O'Neil DW. Use of monoclonal antibodies to enumerate spirochetes and identify Treponema denticola in dental plaque of children, adolescents and young adults. Oral Microbiol Immunol 1991; 6: 97-101.

69. van Poperin N, Lopatin DE. Slot immunoblot assay for detection and quantitation of periodontal disease-associated microorganisms in dental plaque. J Clin Microbiol 1991; 29 $2554-2558$.

70. Kearns EA, Simonson LG, Schutt RW, Johnson MJ, Neil LC Characterization of monoclonal antibodies to two Treponema denticola serotypes by the indirect fluorescent-antibody assay. Microbios 1991; 65: 147-153. 
71. Amann RI, Krumholz L, Stahl DA. Fluorescent-oligonucleotide probing of whole cells for determinative, phylogenetic and environmental studies in microbiology. J Bacteriol 1990; 172: $762-770$.

72. Melvin LW, Assad DA, Miller GA, Gher ME, Simonson L, York AK. Comparison of DNA probe and ELISA microbial analysis methods and their association with adult periodontitis. $J$ Periodontol 1994; 65: 576-582.

73. Moncla BJ, Motley ST, Braham P, Ewing L, Adams TH, Vermeulen NMJ. Use of synthetic oligonucleotide DNA probes for identification and direct detection of Bacteroides forsythus in plaque samples. J Clin Microbiol 1991; 29: 2158-2162.

74. Riviere GR, Wagoner MA, Baker-Zander SA et al. Identifica- tion of spirochetes related to Treponema pallidum in necrotizing ulcerative gingivitis and chronic periodontitis. $N$ Engl $J$ Med 1991; 325: 539-543.

75. Riviere GR, Elliot KS, Adams DF et al. Relative proportions of pathogen-related oral spirochaetes (PROS) and Treponema denticola in supragingival and subgingival plaque from patients with periodontitis. J Periodontol 1992; 63: 131-136.

76. Rosenstein DI, Riviere GR, Elott KS. HIV-associated periodontal disease: new oral spirochaete found. J Am Dent Assoc 1994; 124: 76-80.

77. Riviere GR, Weisz KS, Adams DF, Thomas DD. Pathogenrelated oral spirochaetes from dental plaque are invasive. Infect Immun 1991; 59: 3377-3380. 